\title{
EXPERIENCES WITH HERMANN'S TORTOISE (TESTUDO HERMANNI) MICROCHIPPING IN SLOVENIA - SHORT COMMUNICATION
}

\author{
Alenka DovČ $^{1 *}$, Mateja STVARNIK ${ }^{2}$, Urška MAVRI ${ }^{3}$, Gordana GREGURIĆ-GRAČNER ${ }^{4}$ \\ and Iztok TOMAŽIČ ${ }^{5}$
}

${ }^{1}$ Institute for Health Care of Poultry and ${ }^{2}$ Unit for Administrative Legal Affairs, Veterinary Faculty, University of Ljubljana, Gerbičeva 60, 1000 Ljubljana, Slovenia; ${ }^{3}$ Slovenian Environment Agency, Ministry of the Environment and Spatial Planning, Ljubljana, Slovenia; ${ }^{4}$ Department of Animal Hygiene, Behaviour and Welfare, Faculty of Veterinary Medicine, University of Zagreb, Zagreb, Croatia; ${ }^{5}$ Department of Biology, Biotechnical Faculty, University of Ljubljana, Ljubljana, Slovenia

(Received 29 May 2015; accepted 28 October 2015)

This study describes experiences obtained with microchipping of Hermann's tortoises in Slovenia. Over a period of three years, a total of 5,128 Hermann's tortoises from parental breeding stock were microchipped. Microchips were implanted subcutaneously in the left inguinal region. During the application of microchips, males were bleeding in $2.6 \%$ and females in $1.4 \%$ of the cases. Bleeding frequency was related to sex, animal size and environmental temperature at the time of microchipping. The presence of microchips was followed up over a period of several years. At the control check conducted a few years later, all previously microchipped tortoises were included. Out of the entire parental breeding stock, 235 (4.6\%) had lost their microchips, thus 63 males $(5.7 \%)$ and 172 females $(4.3 \%)$ were unmarked. The possible reasons for microchip loss are migration or inactivity of the implanted microchips.

Key words: Animal identification systems, tortoises, microchipping, defects

According to the national legislation of Slovenia entitled 'Rules on the marking of animals of wild species kept in captivity' (Official Gazette of the Republic of Slovenia, No. 58/04), mammalian, bird and reptile species listed in Annex A to Council Regulation (EC) Number 338/97 on the protection of species of wild fauna and flora by regulating trade therein, must be marked. Hermann's tortoise (Testudo hermanni) is covered by Regulation (EC) No. 338/97 and listed in Annex A. The main threats to Hermann's tortoise are loss of habitat, pollution, urbanisation, tourism, pet trade, road mortality, and potential disease impacts from released pet tortoises (Stubbs, 1989; Willemsen, 1995). Rules on the marking of animals of wild species kept in captivity also stipulate that animals lighter

*Corresponding author; E-mail: alenka.dovc@vf.uni-lj.si; Phone: 00386 (1) 477-9250; Fax: 00386 (1) 477-9339 
DOVČ et al.

than $200 \mathrm{~g}$ and turtles with plastrons shorter than $100 \mathrm{~mm}$, should not be marked with microchips. Microchipping is one of the most common and reliable methods of marking an animal uniquely. The technique has many advantages: easy to read, durable, and has a small percentage of loss or dysfunction (Bizjak, 2004).

Previous research reported in the literature involved only small groups of up to 500 tortoises (Buhlmann and Tuberville, 1998; Gibbons and Andrews, 2004; Gál, 2006; Hellebuyck et al., 2013). The internationally agreed site of microchip application in tortoises is the left hind leg. In large species, it is administered subcutaneously in the tarsal region (Jessop, 2000). We have confirmed that application in the inguinal region is a safe and efficient method for small tortoises, although Redrobe et al. (1999) claimed that the best choice is application in the quadriceps extensor muscle.

\section{Materials and methods}

This study was performed on a parental breeding stock of 5,128 Hermann's tortoises (Testudo hermanni), designated for trade as pet animals in the years 2005 through 2007. Microchips manufactured by Trovan Ltd. (United Kingdom) were applied. To check the correct application of microchips, a highpowered handheld reader ARE-H5 (Trovan Ltd., United Kingdom) was used. Only clinically healthy tortoises were microchipped subcutaneously in the inguinal region. Tortoises were not sedated or anaesthetised prior to the application as described before (Jessop, 2000). The best way was to insert the needle in cranial direction, parallel to the femur. The correct position for microchip application is shown in Fig. 1.

Microchipping was done in accordance with the 'Rules on the marking of animals of wild species kept in captivity' (Official Gazette of the Republic of Slovenia, No. 58/04).

The data were analysed using Microsoft Excel software. The statistical differences in the loss of microchips according to sex and year of microchipping were calculated using $\chi^{2}$ test with IBM SPSS Statistics programme, version 20. Values of $\mathrm{P}<0.05$ were considered to be statistically significant.

\section{Results and discussion}

The average incidence of bleeding after the application of microchips was $2.6 \%$ in males and $1.4 \%$ in females. Hellebuyck et al. (2013) reported a $6.7 \%$ bleeding rate after the application of microchips. The percentage incidence of bleeding by month is shown in Fig. 2. Tortoises were microchipped in the period from April to October. For animal welfare reasons, females should be handled 
very carefully during the main hatching season (May), because inappropriate and rough handling may disrupt the hatching process. The highest bleeding rate was $4.4 \%$ in males in October and $2.1 \%$ in females in April. The average incidence of bleeding was higher in males than in females. The reason for the higher frequency of bleeding in males was mainly their smaller size, which made it more difficult to find the correct and proper depth of application in males. Males are significantly smaller than females at the same age, and are more energetic. Tortoises of the same age were always microchipped at the same time. In April and June six years old, in July five years old, in August twenty years old, in September fourteen years old, and in October thirty-one years old tortoises were microchipped. Only in April did we notice a higher frequency of bleeding in females than in males. This result was insignificant and can be neglected. We assume that differences in age and size could be the reason why we cannot compare the differences of microchipping complications by month. A possible reason for the higher percentage of bleeding (4.4\%) in males in October could be their preparation for hibernation. Males begin the process of hibernation earlier than females (personal communication by the breeder), so handling them in that period is more stressful. They draw their legs under the carapax, so it is necessary to pull the legs out. Males react to this with a strong defence reaction and movement, which can result in the damage of vessels.

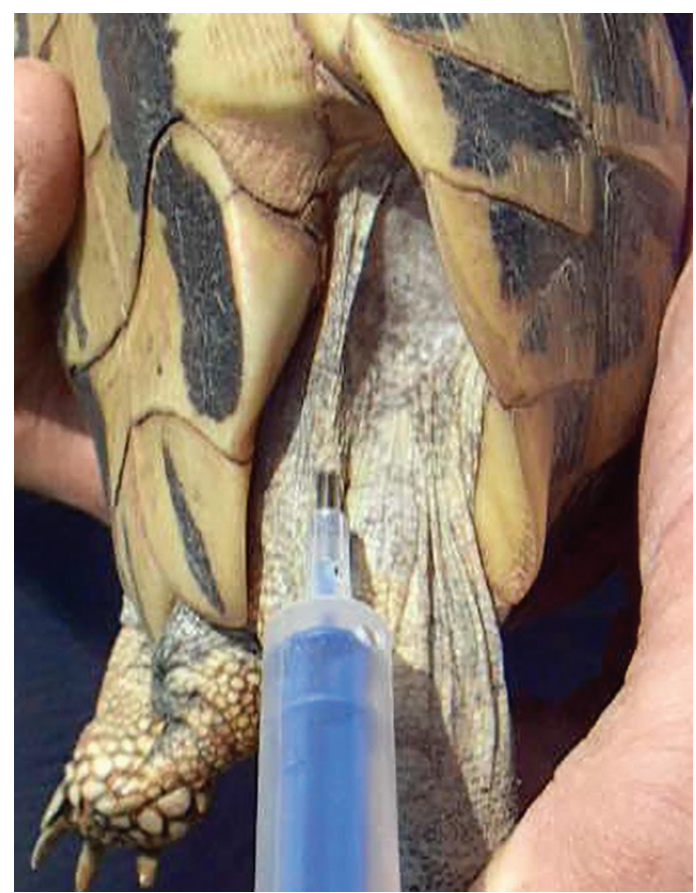

Fig. 1. Application of the microchip in the left inguinal region 
DOVČ et al.

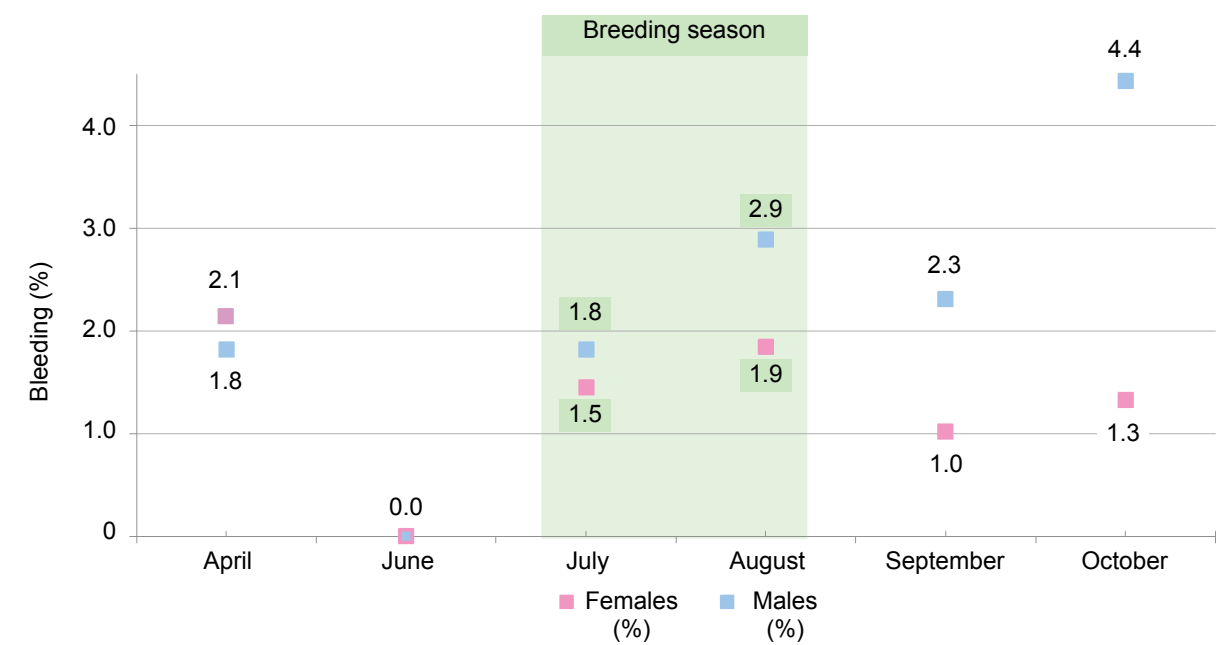

Fig. 2. Bleeding during microchipping in the parental breeding stock of Testudo hermanni shown by month in a four-year-long period

At lower temperatures (below $12{ }^{\circ} \mathrm{C}$ ) and in rainy weather, we observed that the tortoises drew their legs into the shell. Application of a microchip was not always possible, especially in males that were smaller than females in adult age. In these cases, microchips were administered subcutaneously at the tail base just below the carapax and parallel to its caudal edge. No difference among applications into various locations was observed.

Over the first few days after the administration of microchips, wound healing, the occurrence of myiasis (Fig. 3), the formation of abscesses and other secondary infections were monitored. Cases of myiasis were treated in 247 (4.8\%) cases and abscesses in 20 cases. Abscesses and secondary infection, especially during the rainy season, were expected. In practice, they were recorded only in $0.4 \%$ of the tortoises. Obvious migration of the microchip under the rib arch and its elimination in the cervical part of the carapax was observed only in one case. Myiasis, abscesses and migration represent $5.2 \%$ of interventions and medical complications. In the literature it is recommended to disinfect the application site prior to microchip application. After microchipping, the tissue has to be glued with adhesive. If bleeding occurs, fluid therapy has to be provided. Complications appeared sooner, because the outer layers of the skin are inelastic in reptiles. A 24-hour observation of animals is recommended (Redrobe et al., 1999; Jessop, 2000; Hellebuyck et al., 2013). Considering the results of the present study, gluing of the skin with a special adhesive at the application site is not necessary in tortoises. 


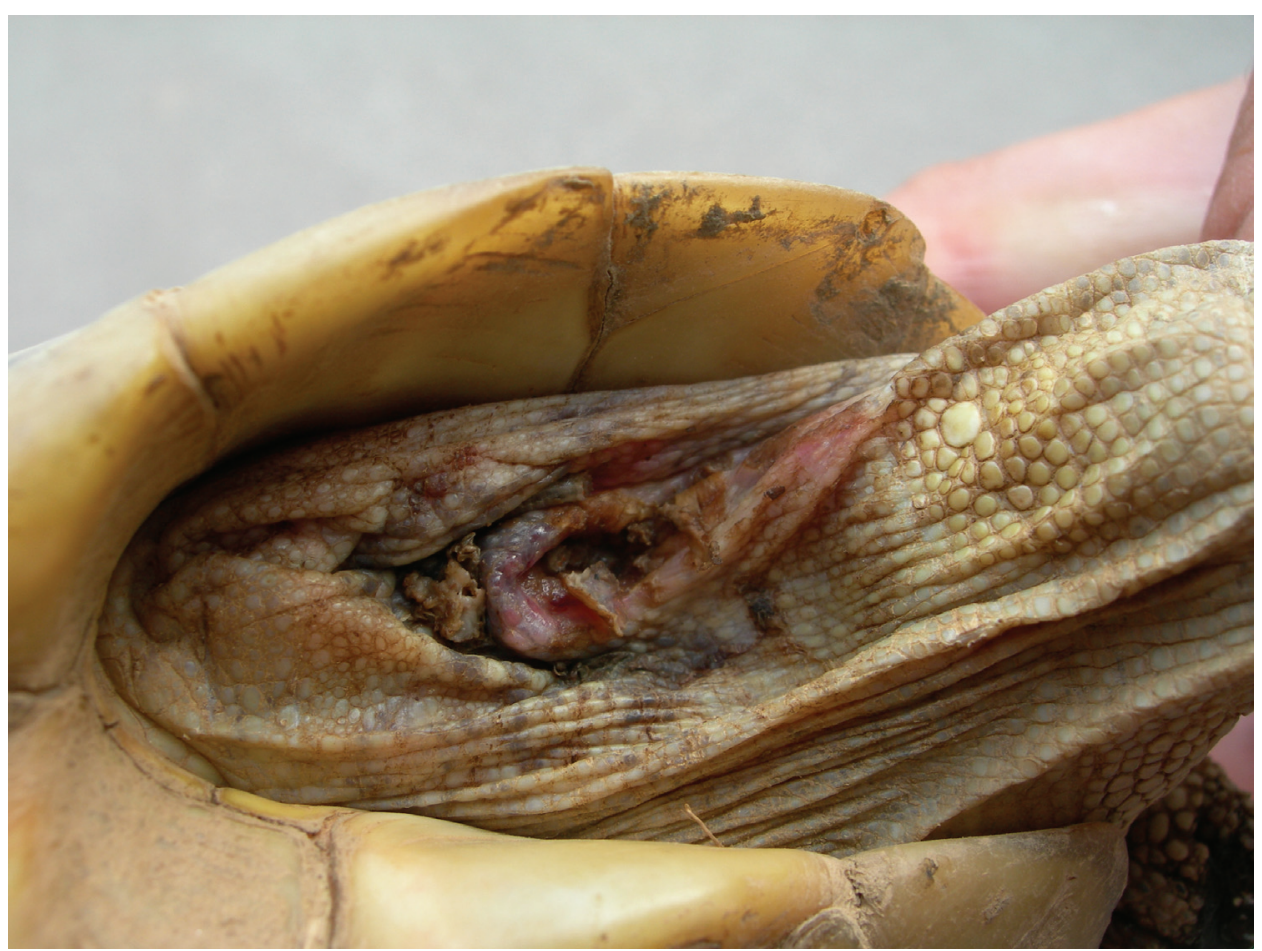

Fig. 3. A complication (myiasis) a few days after microchip application

In 2010, it was determined that over a period of time (i.e. three, four or five years) a loss of microchips occurred. A total of 235 (4.6\%) microchips were unreadable or lost. The proportion of microchips lost was $5.7 \%$ in males and in $4.3 \%$ in females (Table 1). No statistically significant difference in the loss of microchips was found between the two sexes $\left(\chi^{2}=0.078, \mathrm{P}=0.781\right)$. One of the reasons for the higher proportion of microchip loss in males was the more frequent bleeding and consequent microchip loss within a few days after the microchipping procedure. At low temperatures, in rainy weather and at dusk tortoises very often buried themselves into the ground. This could result in non-sterile application, abscess formation and the consequent loss of the microchip over a long period. Gál (2006) described early and late complications of microchip implantation in tortoises. In addition to bleeding complications and abscesses, he also demonstrated embolism, nerve damage, paralysis, and urolithiasis. In our study myiasis was observed. To prevent such complications in the future, for animal welfare reasons we recommend daily observation for at least one week after the microchip implantation. Other possible reasons for microchip loss seen over the years were migration and elimination or inactivity of the implanted microchips. When we checked microchips (in 2010) we could not distinguish between the 
loss of microchips and their inactivity. During diagnostic procedures (X-ray) performed because of dystocia we noted that some females had a microchip which was inactive. Investigations have not yet been carried out systematically but so far only three cases have been noted in which microchips were still present in these tortoises.

Table 1

Microchip loss shown in the years of study in the parental breeding stock of Testudo hermanni males and females

\begin{tabular}{|c|c|c|c|c|}
\hline Sex & Year & $\begin{array}{l}\text { Tortoises } \\
\text { (number) }\end{array}$ & $\begin{array}{l}\text { Loss of microchips } \\
\text { (number) }\end{array}$ & $\begin{array}{l}\text { Loss of microchips } \\
(\%)\end{array}$ \\
\hline \multirow[t]{4}{*}{ Males } & 2005 & 40 & 6 & 15.0 \\
\hline & 2006 & 170 & 20 & 11.8 \\
\hline & 2007 & 903 & 37 & 4.1 \\
\hline & All years together & 1,113 & 63 & 5.7 \\
\hline \multirow[t]{4}{*}{ Females } & 2005 & 100 & 2 & 2.0 \\
\hline & 2006 & 730 & 46 & 6.3 \\
\hline & 2007 & 3,185 & 124 & 3.9 \\
\hline & All years together & 4,015 & 172 & 4.3 \\
\hline \multirow[t]{4}{*}{ Both sexes } & 2005 & 140 & 8 & 5.7 \\
\hline & 2006 & 900 & 66 & 7.3 \\
\hline & 2007 & 4,088 & 161 & 3.9 \\
\hline & All years together & 5,128 & 235 & 4.6 \\
\hline
\end{tabular}

By ensuring the welfare of tortoises through suitable accommodation before and immediately after the application of a microchip, gentle and careful handling as well as microchipping during the month when it was shown to be free of bleeding, can significantly contribute to the success of tortoise microchipping in farms.

\section{Acknowledgement}

The authors would like to thank the breeder of the tortoises for the co-operation provided during this study.

\section{References}

Bizjak, M. (2004): Microchips and identification of wild animals in captivity. In: Vlahović, K. and Marinculić, H. (eds) First Croatian-Slovenian Symposium about Exotic and Wild Animals. Croatian Veterinary Society and Slovenian Veterinary Association, Zagreb, Croatia. pp. 8-9. Buhlmann, K. A. and Tuberville, T. (1998): Use of passive integrated transponder (PIT) tags for marking small freshwater turtles. Chelonian Conserv. Biol. 3, 102-104. 
Gál, J. (2006): Complications of microchip implantation in tortoises. Emys 13, 6-11.

Gibbons, J. and Andrews, K. (2004): PIT tagging: simple technology at its best. BioScience 54, 447-454.

Hellebuyck, T., Pasmans, F., Van Caeelenberg, A., Van Looy, M. and Martel, A. (2013): Assessing the use of microchip transponders as a marking method in juvenile Hermann's tortoises (Testudo hermanni). J. Herpetol. Med. Surg. 23, 32-36.

Jessop, M. (2000): Procedure of microchipping chelonians. J. Small Anim. Pract. 41, 138-139.

Redrobe, S., Littlewood, A., Divers, S., Jessop, M., Keeble, E., Malley, D., Davis, R. R. and Scott, P. (1999): Microchipping tortoises. Vet. Rec. 145, 504.

Stubbs, D. (1989): Testudo hermanni, Hermann's Tortoise. In: Swingland, I. R. and Klemens, M. W. (eds) The Conservation Biology of Tortoises. Gland, Switzerland. pp. 34-36.

Willemsen, R. E. (1995): Status of Testudo hermanni in Greece. In: Ballasian, D. (ed.) Red Data Book on Mediterranean Chelonians. Edagricole - Edizioni Agricoli, Bologna, Italy. pp. $110-118$. 